\title{
Modernization of Conventional Spiral Wound Channel - A Tool to Escape Fouling, Expand Membrane Life and Increase Recovery
}

\author{
Alexei Pervov*
}

\author{
Department of Water Supply, Moscow University of Civil Engineering, Moscow, Russian Federation
}

\begin{abstract}
The survey shows that high operational costs of membrane facilities and large amounts of concentrate effluents are mainly attributed to fouling and scaling. The research of scaling and fouling mechanisms shows that these processes depend not only on hydrodynamic factors, but on membrane type and channel geometry. However, the main disadvantages of the modern $\mathrm{RO}$ techniques are connected with membrane fouling, concentrate flow, and complicated design. The main ways to develop new fouling-free techniques are outlined and suggest a new concept of modified "open-channel" spiral wound membranes. Successful attempts were undertaken by the author to modify spiral wound membrane channels to limit fouling and scaling potentials of membrane modules. Elimination of spacer mesh from the feed channels eliminates "dead" regions that provide scaling and fouling conditions whilst also reducing the risk of particle "trapping" and associated dramatic cross flow resistance increase. High recoveries could also be reached due to strong stability of calcium carbonate and sulphate solutions. Introduction of a new "open-channel" configuration offers new perspectives to escape fouling and develop a novel technique to treat water with high fouling and scaling potential. This novel concept of spiral wound module with an "open channel" design has been developed, field-tested and introduced into practice.

A test procedure is described that enables us to compare fouling propensities of RO facilities tailored with different membrane types and channel configurations. Cross-flow resistance increase, scaling, and fouling rates and flux decrease are predicted for different feed water compositions. Introduction of new "open channel" spiral wound module into desalination practice enables us to considerately expand the application area of RO techniques.
\end{abstract}

Keywords: Filtration mode, membrane fouling, nanofiltration, reverse osmosis, ultrafiltration.

\section{INTRODUCTION}

Modern membrane techniques (UF, NF, RO) have demonstrated high efficiency in removal of suspended matter, bacterial, as well as organic and mineral ingredients containing in natural water. Meanwhile, certain problems of membrane fouling arise, resulting in shortening of membrane life and reduction in product flow. Despite high efficiency in drinking water production, strong skepticism exists towards perspectives of using $\mathrm{RO}$ and NF membrane techniques in municipal water treatment. This attitude is attributed to existing membrane spiral wound module operation that requires significant pretreat-ment, high chemical consumption, and therefore, high operational costs. To prevent formation of fouling layers on membrane surface and cake resistance increases, a number of measures are applied, such as backflushes, chemical cleanings, feedwater pretreatment. Despite these measures, fouling remains a major factor that determines operational costs.

Natural surface water contains high concentra-tions of suspended and colloidal matter with different particle size distribution, as well as dissolved organics (mainly humic substances) with various

*Address correspondence to this author at the Department of Water Supply, Moscow University of Civil Engineering, Moscow, Russian Federation

E-mail: ale-pervov@yandex.ru molecular weights. Different foulants (sparingly soluble salts, bacterial, organic, and colloidal matter) cause different fouling mechanisms. The conclusion that membrane fouling depends not only on hydraulic factors (such as concentration polarization effect, flow turbulence, cross-flow velocity), but also on channel configuration was claimed in publications as early as $1991[1,2]$ and this led to re-evaluating the layout of the spiral wound module.

The general construction and flow pattern in conventional spiral wound modules are shown in Figure 1. The module is made of membrane leaves that are wound around the product tube, resulting in a spiral configuration [1]. Each leaf consists of two sheets of membrane with a sheet of tricot between to act as the product water carrier. Three sides of the leaf are glued to form an envelope. Plastic netting between the leaves serves as the feed channel spacer that enhances mixing. Tricot extending from the open end is attached to a perforated product tube that contains holes to collect product water.

The development of new, ecologically safe, chemical-free water treatment techniques is the most important challenge for membranes.

For success, modernization of conventional membrane modules is needed. 
Spiral wound configuration is recognized as optimal due to high surface per unit volume of the module. Spiral wound configuration is widely applied in most water installations but is nevertheless considered incapable, due to fouling hazard, of directly treat surface water that contains suspended and organic matter.

During the last few years, a new membrane process has been introduced into water supply practice that directly treats surface water with nanofiltration membranes without pretreatment [3-5].

As was reported in $[3,7]$, the efficiency and reliability of this fouling-free operation are attributed mainly to hydrodynamic flow conditions in tubular and capillary membrane channel that provide enough shear force for the particles not to foul the membrane. These conditions are provided by channel configuration (using capillary or tubular membranes), by high cross-flow velocities, as well as through application of hydraulic flushings (including air scouring) and timely chemical cleanings. But these systems are not widely used due to high capital and operating (energy) costs.
Spiral wound configuration is recognized as optimal both economically and technically, as it uses flat sheet membranes and provides high membrane /module ratio at significantly low cost. However, the existing spiral wound module configuration used for RO, NF and UF applications is very susceptible to fouling, which makes it useless to treat water containing suspended and colloidal matter. The main disadvantages of spiral wound modules are attributed to presence of separation spacer mesh in the feed channel as it traps fouling particles and increases the pressure drop (Figure 1). The mechanism of mesh performance and its influence on scaling (fouling) process initiation has been proposed in $[1,2]$. The places (spots) where mesh contacts membrane surface provide dead areas without cross-flow, resulting in high concentration increase at the membrane surface within this area. Concentration polarization increases and initiates the formation of crystals and coagulation of colloids inside these dead areas. Membrane autopsies performed at different stages of fouling formation enabled us to trace crystals' trajectories withdrawn from the deadlocks and subsequently sediment on the membrane surface. Organics and colloidal matter coagulate and sediment

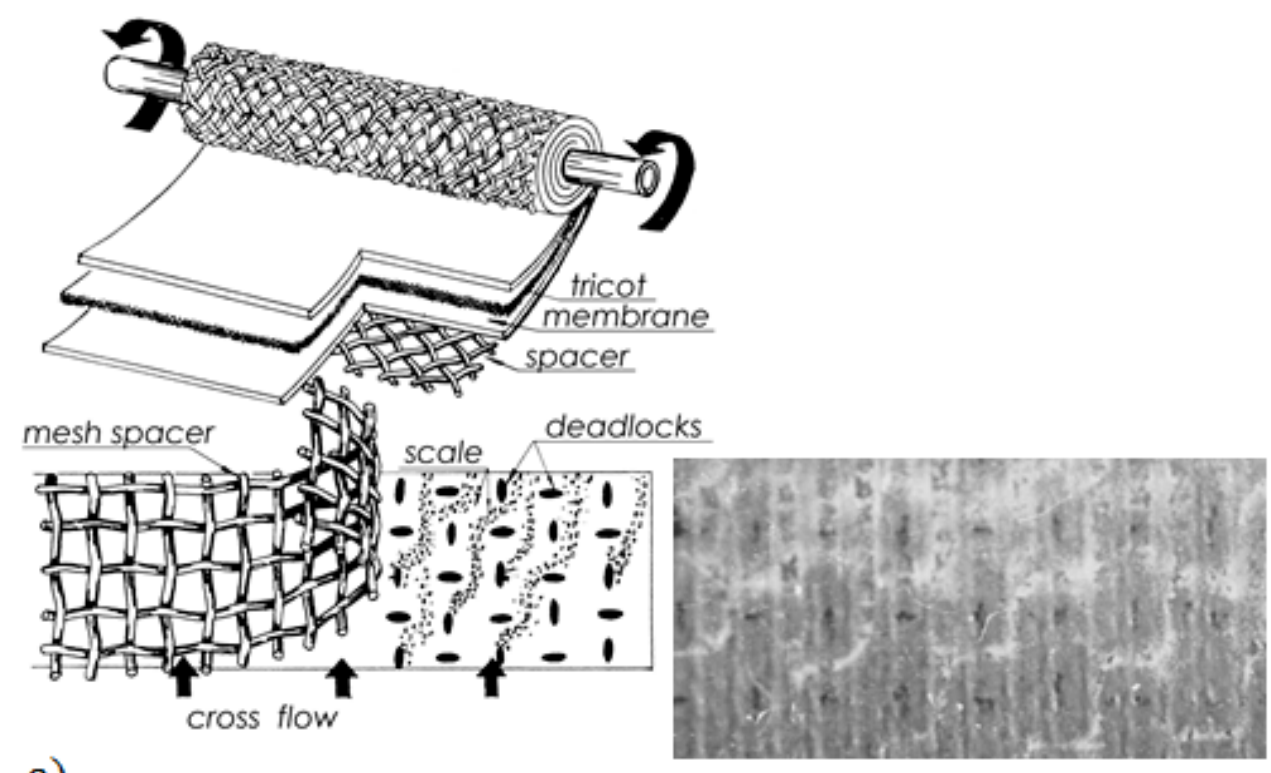

a)

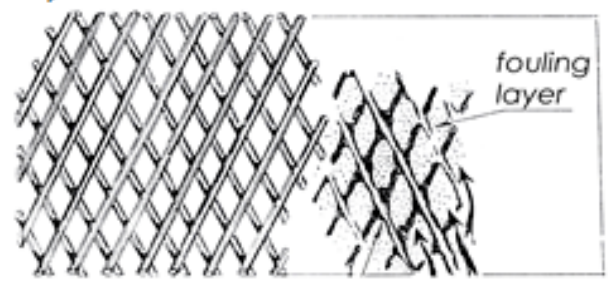

b)

Figure 1: Fouling and scaling: influence of space. Formation of crystals in dead areas: a) - formation of scale crystals; $\mathbf{b})$ particle trapping and fouling layer formation. 


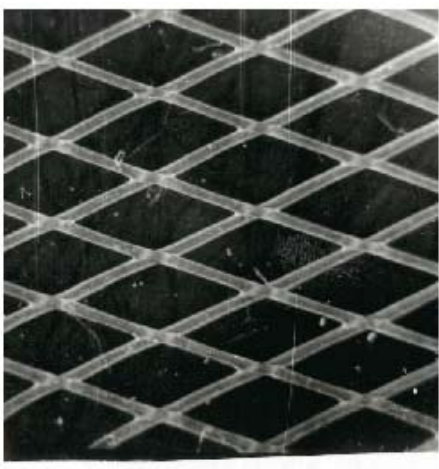

a)
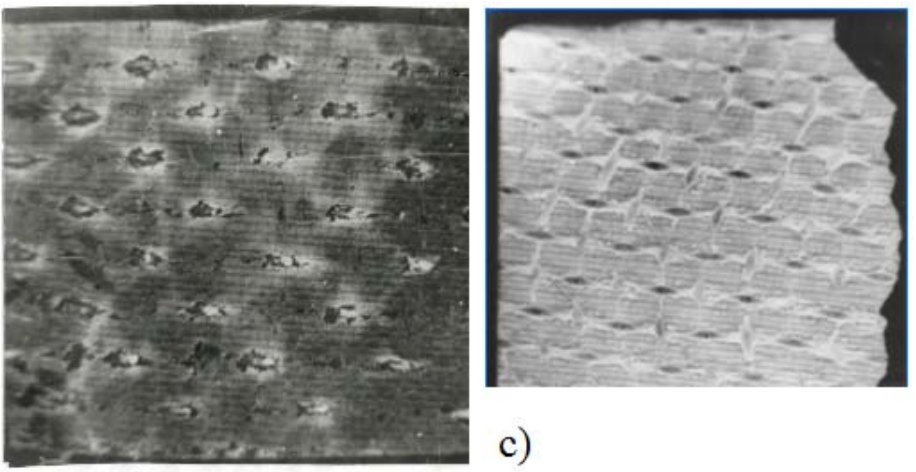

b)

Figure 2: Fouling and scaling in conventional spiral wound membrane module. a) - platted spacer and the order of scale formation areas distribution; b) - correlates to the order of the mesh bundles; c) -the scale layer relief also repeats the spacer configuration.

within dead areas, providing further conditions for particle coagulation and adhesion to the formed layer promoting expansion of the foulant layer around these areas [2].

The investigation of the sparingly soluble salts scaling in RO systems has shown that spiral wound modules are susceptible to scaling due to the contact of spacer mesh with membrane surface $[1,2]$. The contact sites provide additional local resistance to the flow above the membrane surface, lowering flow rates and resulting in concentration increase. The reached supersaturation degrees appear to be sufficient to initiate crystal nucleation. The results of the experimental study suggest that crystals are brought out of the "dead areas" and subsequently sediment on the membrane surface according to suspended particles fouling mechanism. Microscopic observations of membrane surfaces during the scaled-up modules autopsies confirm the suggested scaling mechanism. Figures 1-3 show results of observations obtained by the author during his research devoted to understanding scaling and fouling mechanisms $[1,2]$.

Figure (2a) shows the platted spacer, and the order of scale formation areas distribution shown on Figure (2b) correlates to the order of the mesh bundles. The scale layer relief also repeats the spacer configuration, as shown on Figure (2c).

The scaling process was investigated and simulated in laboratory conditions using a laboratory test cell. The spiral wound module channel was formed by the mesh spacer placed between two membranes. It can be seen that crystals are formed and brought out of the "dead areas" and subsequently sediment on membrane surface, leaving the tracks up to the channel outlet (Figure 3). The laboratory test experience suggests important conclusion that no heterogeneous nucleation occurs on membrane surface. Crystal formation occurs in the bulk solution due to the strong supersaturation values reached in the "dead areas" and follows homogeneous nucleation mechanism. The laboratory experiments using plate-and -frame test cells without a spacer in the channel provided scaling-free performances when operated at calcium sulphate supersaturated solutions.

Thus it becomes possible to develop RO module channel with minimal scaling potential. Safe operation above the saturation limits does not contradict with crystallization theory which states that calcium sulphate and calcium carbonate supersaturated solutions are stable and can tolerate high supersaturation levels without an evidence of nucleation. Polymer membrane surface as well as colloidal waterborne species appear to be inert to initiate heterogeneous nucleation.

Elimination of the mesh could help to develop new types of modules with decreased fouling potential and provide new reliable and efficient techniques for surface water treatment. Despite this obvious fact, this possible solution to modify existing spiral wound modules is still being ignored by most membrane module manufacturers.

Economic efficiencies of membrane desalination units are dependent on capital costs (equipment costs) and operational costs (energy for water pumping, membrane replacement, and chemicals for membrane cleanings and pretreatment).

The existing tubular, filter press, and capillary UF membrane facilities, as applied in RO pretreatment, is very expensive. In addition, very high required crossflow velocities also increase operational costs. This 


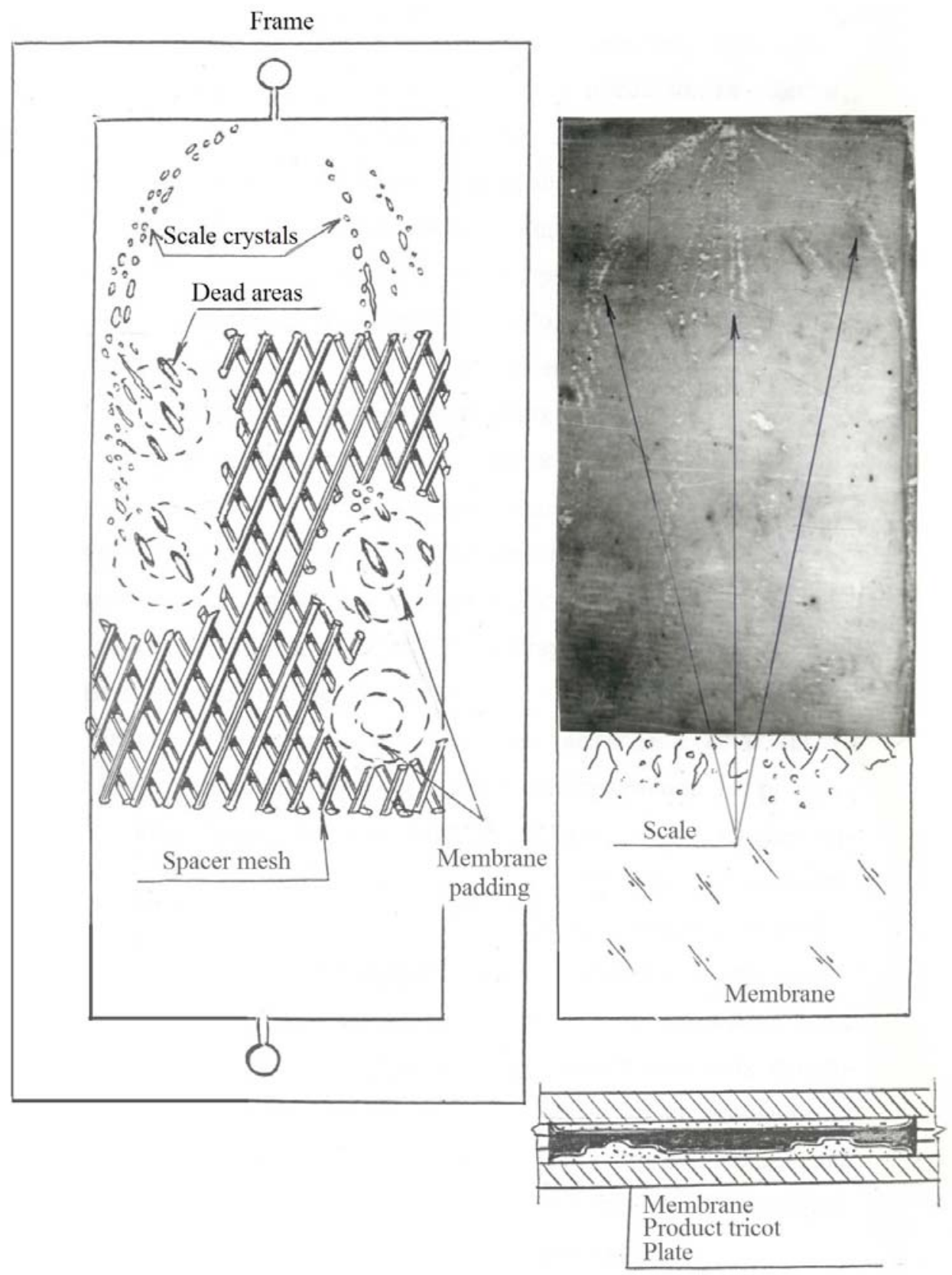

Figure 3: Formation of crystals in "dead areas". The process is simulated in plate-and-frame test cell.

idea was also discussed by Richard Riddle in a report [8] devoted to the development of an open-channel spiral wound module.

In 1991, the "Aqua-Chem" company offered the solution of "open-channel" geometry [8]. Modification of spiral wound module is shown on Figure 4 where the mesh is withdrawn from the channel. A membrane "leaf" that has 365 inch width is divided into four channels, each 10 inch wide and 40 inch long using plastic "ledges" that form channel walls, as shown in Figure 4. This creates a narrower membrane channel, resulting in higher cross-flow velocities in the channel.
The cross-flow velocity values in the "open-channel" modules thus become 4-5 times higher than in conventional channel, providing a shear-off effect for suspended particles.

This paper presents the results research that was conducted to improve conventional spiral wound configuration to treat directly natural water and wastewater without pretreatment. The present work aims to develop a new modified spiral wound configuration with optimum operational characteristics (recoveries, cross-flow velocities, flushing cycle durations, cleaning schedules) to ensure long and 
reliable operation of membrane systems with minimum operational costs.

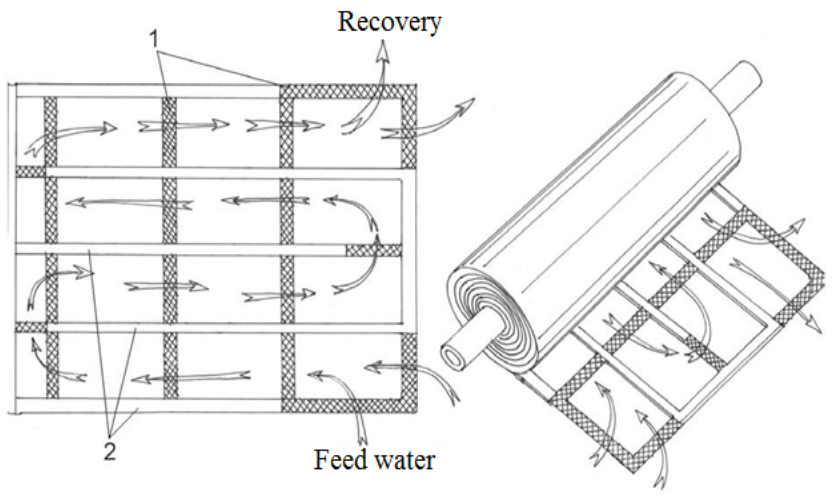

Figure 4: Open channel module suggested by Aqua Chem [8]. 1 - Spacer; 2 - ledges.

The research devoted to introduction of a new membrane technique is not limited only by development and manufacturing of new spiral wound membrane module with decreased fouling propensities, but also includes:

- selection of an optimum operational mode characterized by minimal values of cross-flow velocity corresponding to minimum of chemical cleaning;

- development of an economical operation mode that corresponds to minimum of concentrate and flush water disposal that can be reached with an efficient selection of flushing frequency and duration;

- selection of membrane material with the best surface adhesive characteristics that provide lowest fouling rates with maximum shear-off effect during flushings.

\section{DEVELOPMENT OF AN "OPEN-CHANNEL" MODULE DESIGN}

Different innovations were implemented and tested throughout the research program. Technical considerations to improve membrane channel geometry and avoid formation of "dead areas" are shown on Figures 5 and $\mathbf{6}$. Modernization of the channel is developed by the author and patented.

Various types of spacers and double spacers were tried and tested. To eliminate dead areas and to

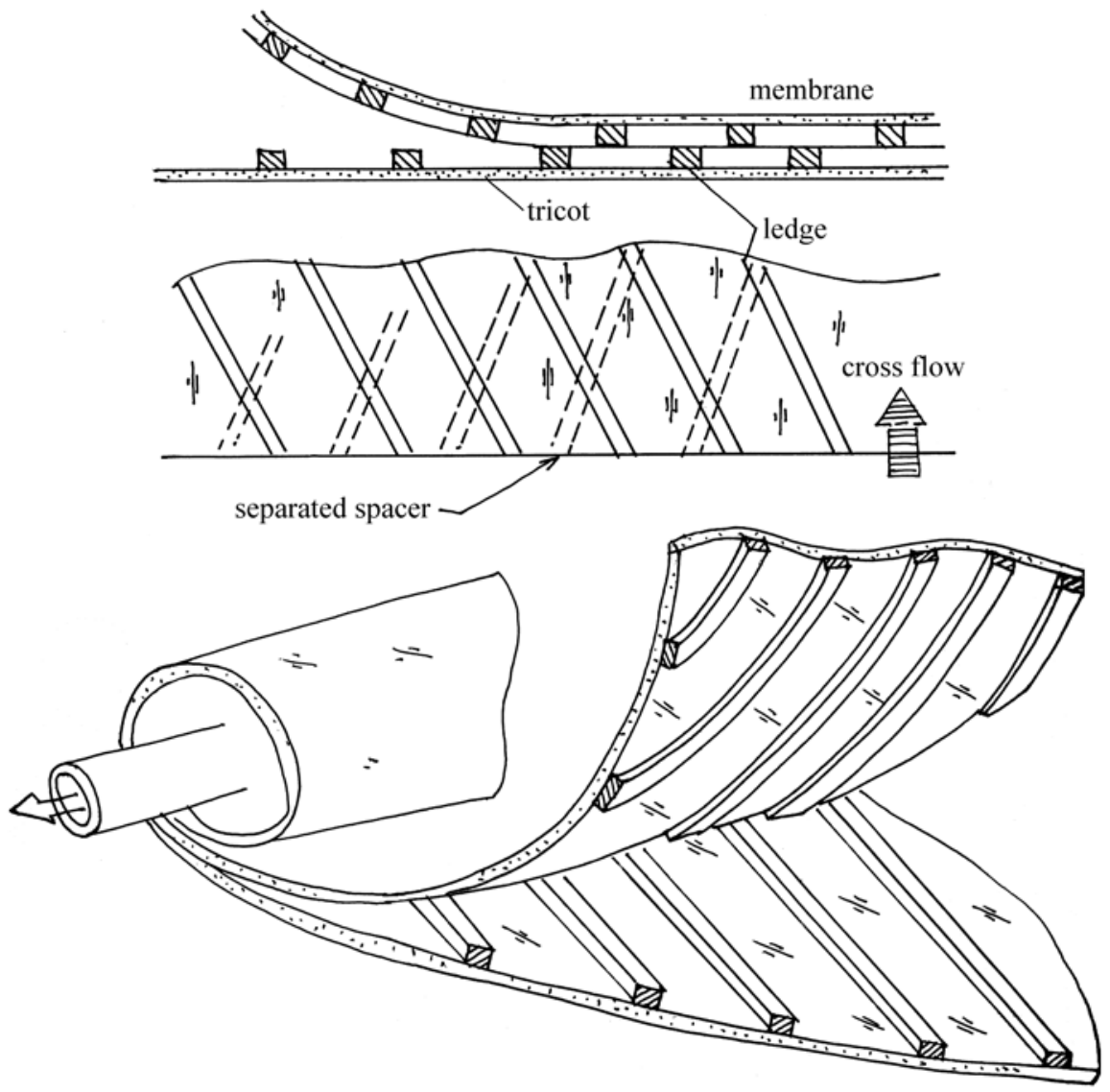

Figure 5: Spiral wound module with open-channel configuration. 
provide low flow resistance, a spacer should not touch membrane surface. One of the best solutions was the idea of "separate" spacer where mesh fibers are glued to membrane surface. RO spacer is a platted mesh where parallel groups of fibers are crossed and welded, forming a rhombic structure (Figures 1 and 2). In our construction, parallel groups of fibers (ledges) on opposite sides of membrane envelope are oriented in different directions (Figure 5). The glued fibers form a rhombus $1.2 \mathrm{~mm}$ wide and $0.35 \mathrm{~mm}$ thick. When a module is rolled, opposite membrane sides are pressed to each other, and ledges separate membrane surfaces, providing enough space for flow with very low resistance. The idea of a channel configuration was already patented and some innovations are being introduced. Several modules of 1812 standard were rolled using various types and configurations of NF and low pressure RO membranes (cellulose acetate, TFC based on polyvinyl alcohol and polyamide). Cellulose acetate asymmetric NF membranes were provided by Vladipore Co. (Vladimir, Russia) and TFC RO membranes were ESPA samples (Hydranautics).

Another new spacer structure is also implemented, as shown in Figure 6.

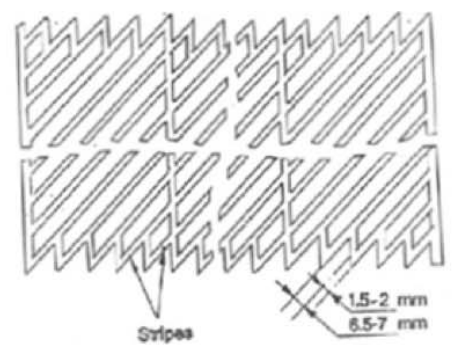

a)

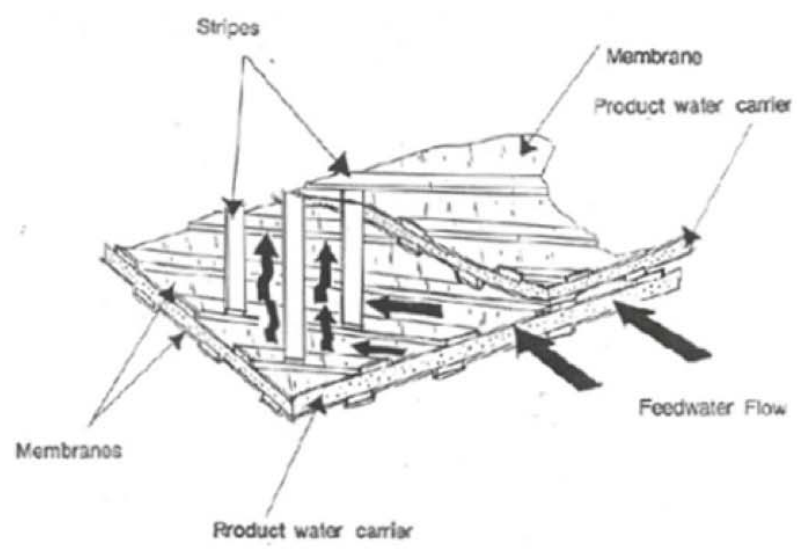

c)
The spacer structure is stamped out of a polymeric film sheet $0.3 \mathrm{~mm}$ thick and comprises parallel $1.5-2$ $\mathrm{mm}$ wide stripes with the 6-7 $\mathrm{mm}$ gap between them. The stripes are oriented under a 45 degree angle to the axial flow direction in the module. The spacer structures are placed on both sides of tricot under membrane sheets, as shown in Figure 6 . The stripes on the opposite sides of the leaf should be directed perpendicularly. The entrance to the feed channel is provided by inserting narrow sheets of plastic netting between the membrane leaves, as shown in Figure 6 . When the pressurized feedwater enters the channel, the membrane, having been pressed to the tricot, follows the relief of the stripes: replicating the shape, flow pattern, and mixing effect of conventional plastic netting spacer's (Figure 1). Since the stripes are made of water non-permeable polymeric material, the contact bundles between upper and lower stripes do not provide concentration increase effect.

\section{EXPERIMENTAL PROCEDURE AND TEST PROGRAM}

The test program included the determination of fouling rates, flushing efficiencies and flow resistance according to a test procedure described earlier $[1,2,10]$.

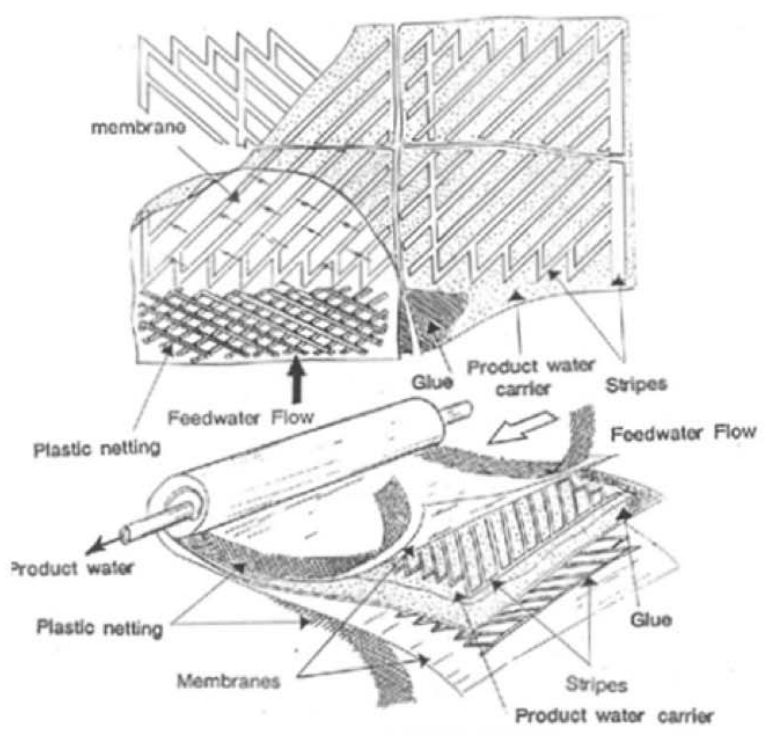

b)

Figure 6: Principles to produce an "open channel" spiral wound module: construction of a new spacer type. 
The experimental program was performed using the membrane laboratory test unit shown in Figure 7. Feedwater is pumped from the tank (1) to a spiral wound membrane module (3) by the pump (2). The working pressure value is controlled by a valve (5) and measured by a pressure gauge (6). Cross-flow velocity is controlled using the by-pass valve (4). The test procedure is conducted in circulating mode whereby reject flow (concentrate) is returned to the tank (1) and product is collected in a separate tank (7). Determination of concentration values in the brine tank and in the product tank enables us to calculate the amount of foulant accumulated in the membrane module and fouling rates. Spiral wound modules of 1812 standard (12" length and 1,8" in diameter) tailored with low pressure RO membranes (BLN-type) manufactured by CSM (Korea) were used in experimental studies for comparison with newly developed modules.

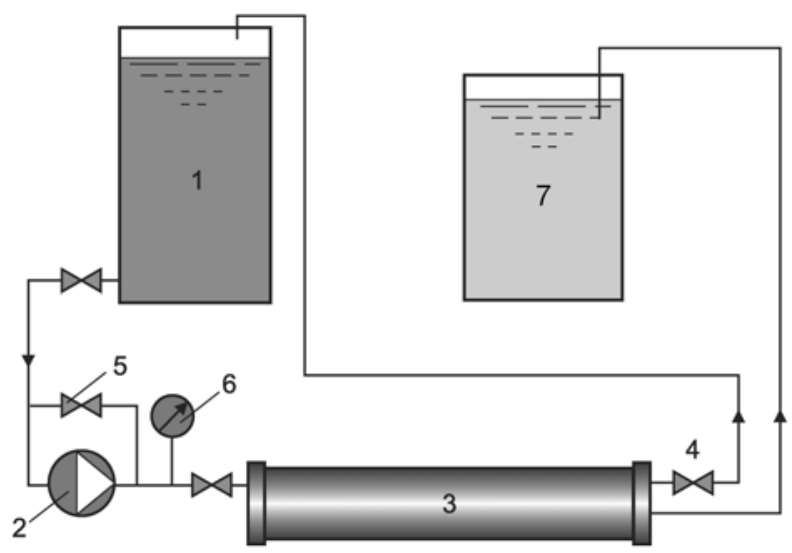

Figure 7: Schematic diagram for NF test unit: 1 - feedwater tank; 2 - high pressure pump; 3 - NF module; 4 concentrate line valve; 5 - by-pass valve for adjusting operational pressure; 6 - pressure gauge; 7 - product tank.

New "open"channel" spiral wound modules were manufactured using the same flat sheetmembranes, having the same dimensions and fitting the same size pressure vessel. Modules were manufactured in accordance with configuration shown on Figure 5 using rolling machine "Model № RS 4040A" supplied by "Hydrocomponents and Technologies", CA.

Natural water (surface and groundwater) was used as test solutions in experiments. To increase fouling and scaling potential of the test solution (to increase hardness, colour or turbidity), natural water was preconcentrated using $\mathrm{RO}$ modules.

Figure 8 shows results of hydrodynamic tests (membrane rejection characteristics versus cross-flow rate values). The depletion of calcium concentration in the feed circulating solution enables us to calculate the amount of scale accumulated in the module (Figure 9). To determine calcium carbonate scaling propensities of RO membrane modules, a test procedure should provide supersaturation conditions as a driving forse for crystallization [10,11]. In described experiments scaling potential was constantly arranged due to operation of the test unit in concentration mode where product water was discharged [12].

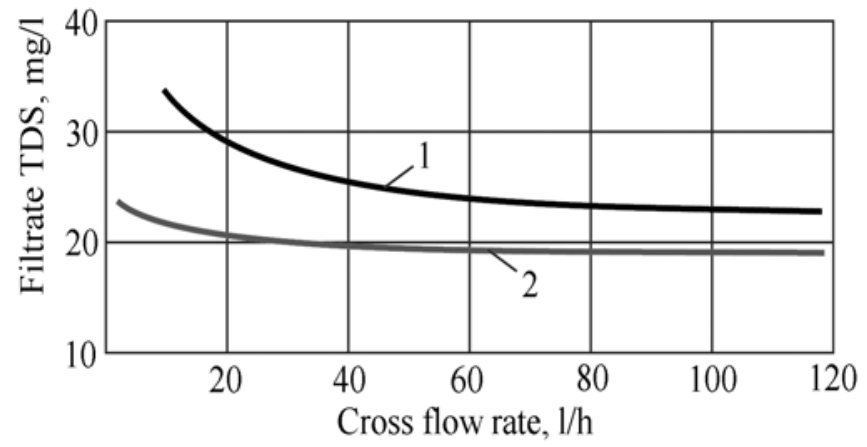

Figure 8: The influence of cross-flow rate on filtrate TDS: 1 conventional module; 2 - open-channel module.

Scale accumulation rates for any time moments of experiment may be determined as tangents of the experimentally obtained curves $[1,2,10]$. Moreover, every moment of experiment corresponds to the definite calcium concentration, i.e. to the definite feedwater composition. The dependencies of scale growth rate values on calcium concentration in the feed are presented in Figure 9, where the performance of conventional spiral wound module is compared with that of the newly proposed type.

The experimentally obtained relationships that describe particulate and organic fouling are shown in Figures 10 and 11. These graphs show the results of particulate (Figure 10) and organic (Figure 11) fouling rate determination depending cross-flow velocities in membrane module. The higher the velocity, the less particular matter is accumulated on membrane surface. Vice versa, organic material is adsorbed on membrane surface more intensively when cross-flow is higher.

To determine calcium carbonate scaling propensities of RO membrane modules, a test procedure should provide supersaturation conditions as a driving forse for crystallization [10,11]. In described experiments scaling potential was constantly arranged due to operation of the test unit in concentration mode where product water was discharged [12]. 


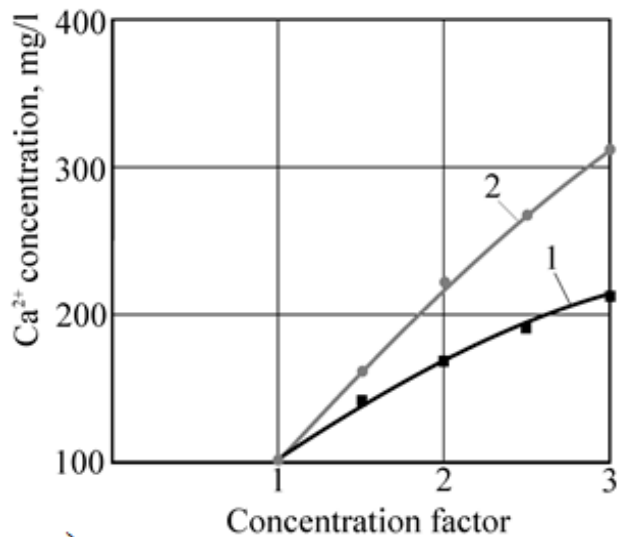

a.)

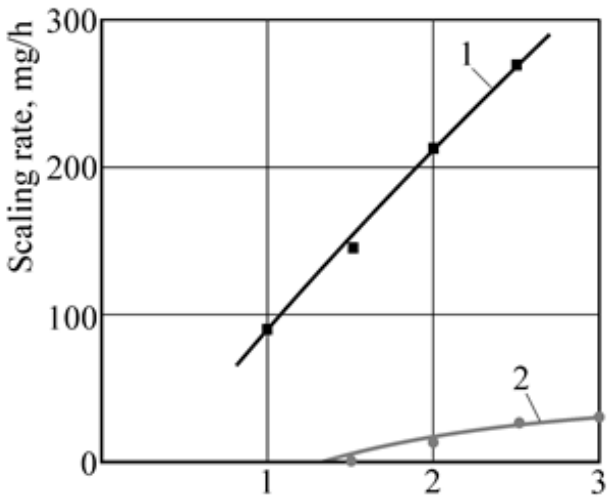

b.)
Concentration factor

Figure 9: The results of scaling rate determination for conventional and open-channel module configuration: a) - conventional module (1812, BLN, "CSM"); b) - open channel module (1812, BLN).

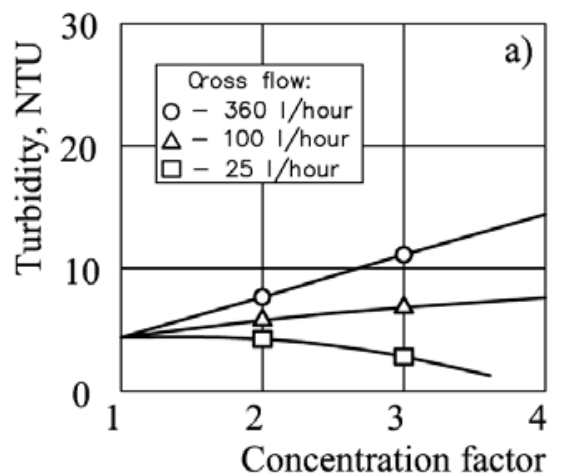

a.)

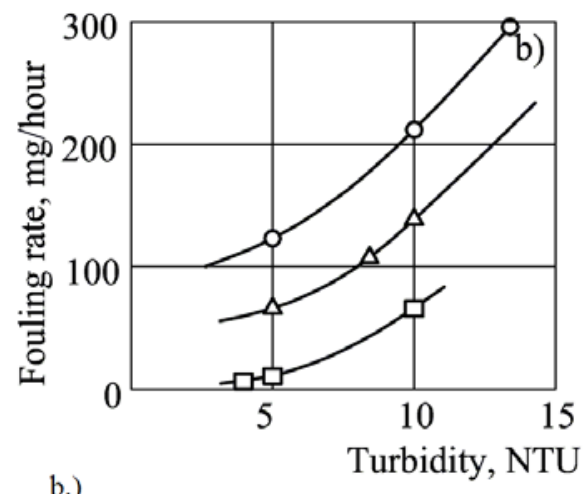

b.)

Figure 10: Determination of particulate fouling rates: a) - turbidity versus concentration ratio; b) - fouling rate versus turbidity.

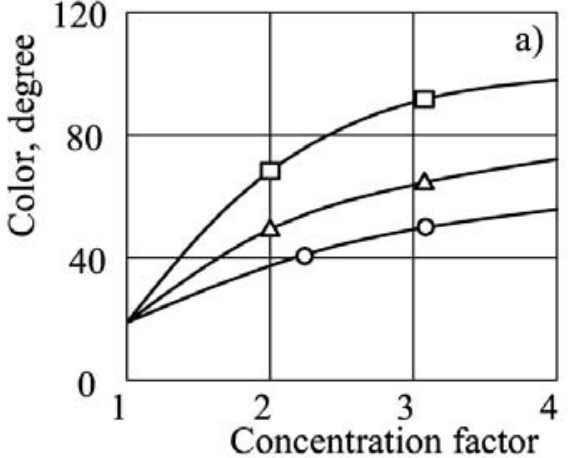

a.)

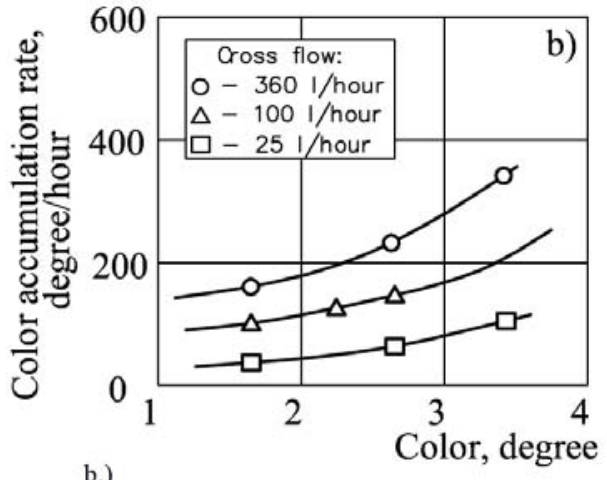

b.)

Figure 11: Dependencies of circulated water color on concentration ratio (a) and organic fouling rate on feedwater color (b).

Comparison of cross-flow resistance values versus cross-flow velocities for conventional spiral wound element and an open-channel module is shown in Figure 12. During the accumulation of foulant on the membrane surface, flow resistance increases and product flow decreases. The amount of accumulated foulant can be detected throughout circulation experiments. Figure $\mathbf{1 3}$ shows flow resistance (pressure drop) values versus flow values graphs for different amounts of particulate foulants in the module. The growth of flow resistance values due to foulant accumulation is shown in Figure 14, where calculations are presented by curves each corresponding to certain cross-flow values.

Applications of hydraulic flushings destroy fouling layers and withdraw foulants from membrane surface by cross-flow velocity increases and water hammer 


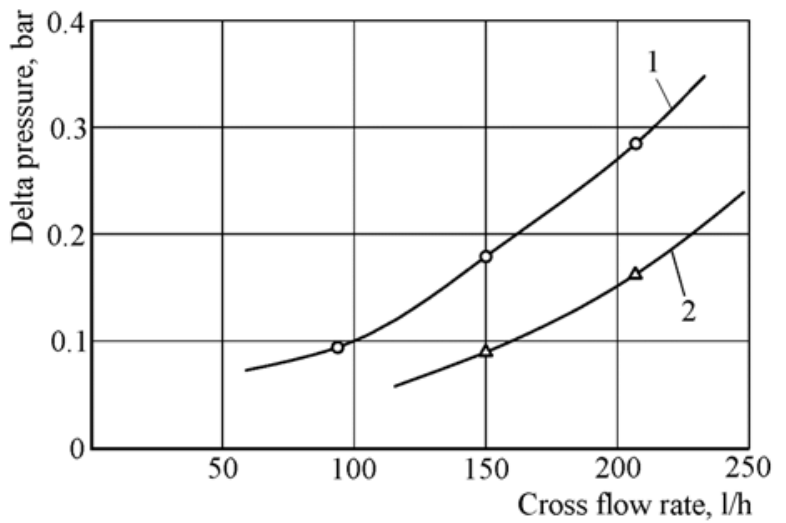

Figure 12: Delta pressure increase versus cross-flow values: 1 - conventional module (1812, BLN, "CSM"); 2 - open channel module (1812, BLN).

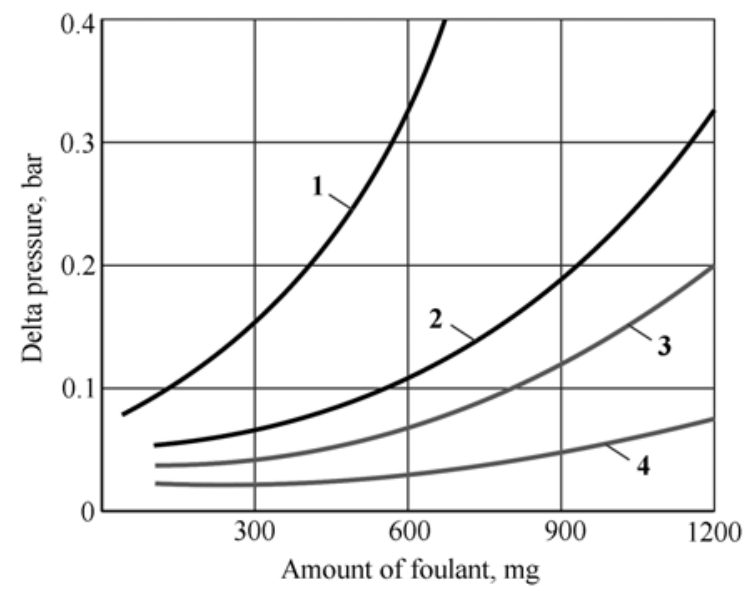

Figure 13: Determination of delta pressure increase during foulant accumulation. 1,2 - conventional module (1812, BLN, "CSM"); 3,4 - open channel module (1812, BLN); cross-flow: $1,3-100 \mathrm{l} / \mathrm{hr} ; 2,4-50 \mathrm{l} / \mathrm{hr}$.

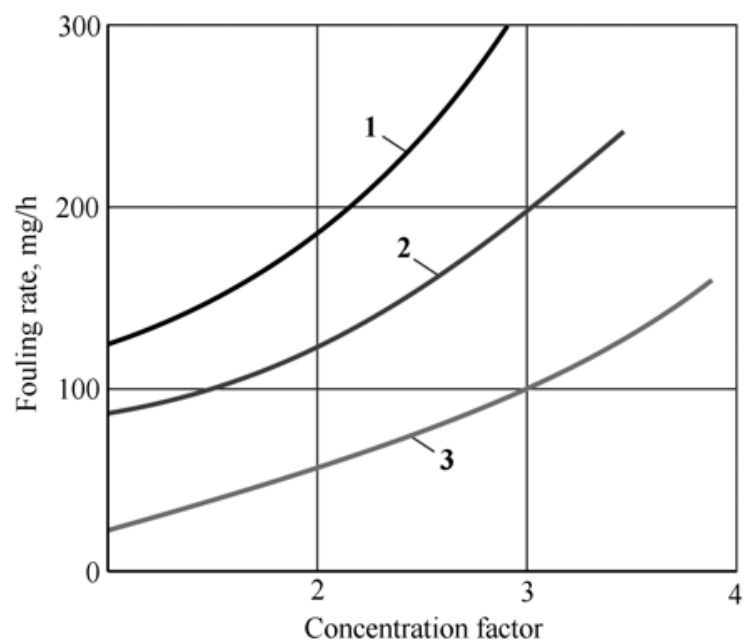

Figure 14: Dependencies of delta pressure increase versus cross-flow and amount of accumulated foulant amount. Cross-flow: $1-360 \mathrm{l} / \mathrm{hr} ; 2-100 \mathrm{l} / \mathrm{hr} ; 3-25 \mathrm{l} / \mathrm{hr}$.

initiations through rapid pressure drops. Figure 15 shows the relationships of product flow values versus time and flow resistance growth versus time where flushings are constantly applied after certain operational time periods. Flushing modes (time between flushes and flushing duration) are very important to maintaining fouling control and product flow on the desired level. Suspended solids concentration, color, recovery, pressure value, crossflow velocities, as well as membrane type and module design are decisive factors that influence operational efficiency and flushing modes.

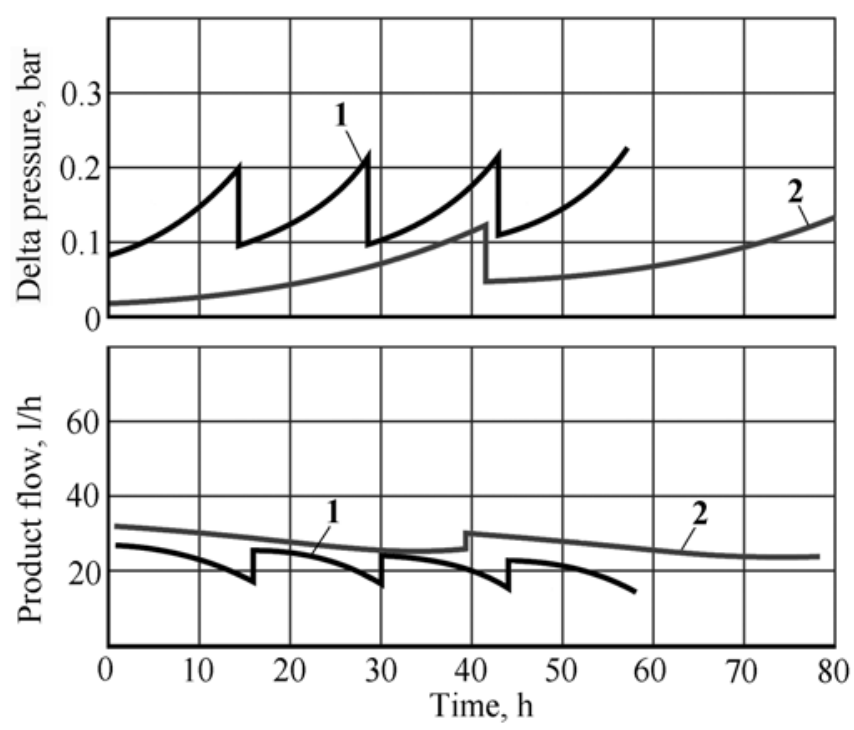

Figure 15: Comparison of: 1 - "standard" and 2 - "open channel" modules performance.

Operational costs depend on the pumping characteristics and energy consumption, reject effluent flow, chemical cleaning schedules (to control fouling) and can be minimized by selecting optimum

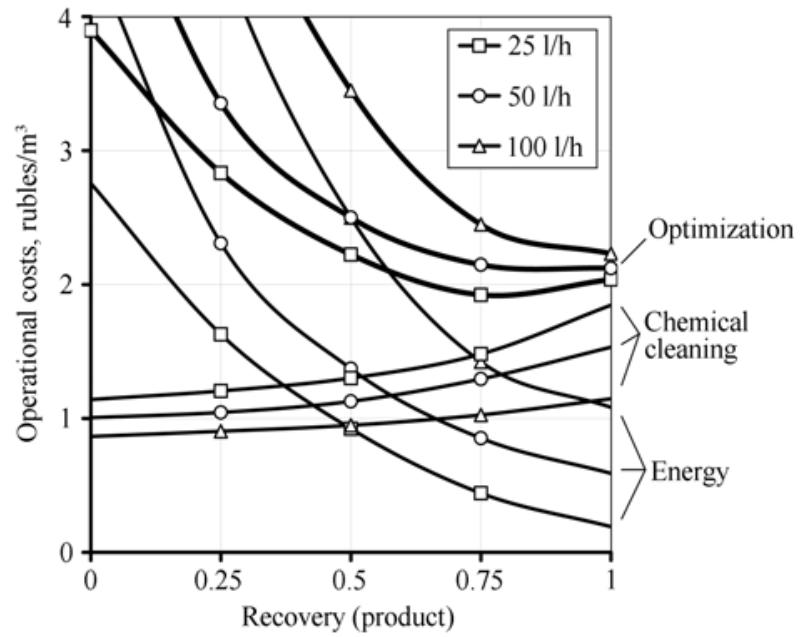

Figure 16: Determination of optimum recoveries and flow modules for NF unit. 
operational conditions. Figure 16 shows an example of determination of optimum recovery values and flow modes. Fouling rates grow as recovery increases and thus cleanings to remove foulants should be applied more often. This increases operational costs, but power consumption decreases as recovery increases, reducing operational costs accordingly. Total operational costs are the result of the sum of both energy and chemical costs.

\section{DISCUSSION OF THE RESULTS}

Suspended and colloidal fouling rates were successfully determined in the circulation mode. Deposition rates depended on the cross-flow velocities that provided shear-force on the particles. Depending on membrane surface properties (hydrophility, surface charge etc.) rates of colloidal and organic matter deposition varies. Research is being conducted to modify membrane surface with the purpose of protecting it from bacteria and particulate adhesion $[13,14]$. Cellulose acetate membranes are less susceptible to organic and colloidal fouling (Figure 17). The mechanism of organic fouling has been widely investigated. It is obviously based on adsorption of organic molecules from water solution.

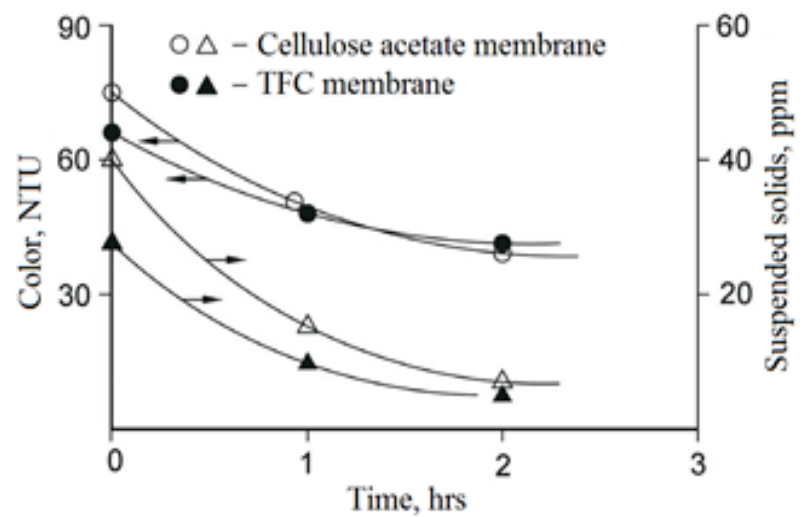

Figure 17: The influence of membrane surface properties on fouling propensities.

Suspended and colloidal particulate fouling depends on cross-flow velocities and rises as cross flow values decrease. Organic sorption provides an opposite relationship: the higher the cross-flow velocity, the higher the adsorption rate. This can have two explanations: first, the colloidal fouling layer blocks the active membrane surface and reduces sorption rate, and second: the sorption process follows the diffusion mechanism and is more complete with higher crossflow velocities.
Hydraulic flushing provides an efficient measure to control fouling. Large amount of colloidal and organic material accumulated during hours of operation is efficiently flushed-off the membrane surface in a few seconds. Meanwhile, analysis of flush water shows that its color is different and depends on operational conditions. Colloidal foulants (mainly surface water humic acids) sorb organics (fulvic acids) using amide and peptic groups. The more foulant is deposited on membrane surface, the higher was the color of the flushing water, and vice versa. It was concluded that organics adsorbed by the foulant were successfully flushed off membrane surface and that organics were more intensively absorbed by the membrane surface than by the fouling layer. Figure $\mathbf{1 8}$ shows the amounts of accumulated colloidal matter and organics, detected in flush water.

Channel geometry is a strong factor that influences membrane performance if fouling occurs. During foulant accumulation, cross-flow resistance grows. When open-channel modules were tested, the observed values of flow resistance increase and product flow drop were significantly lower.

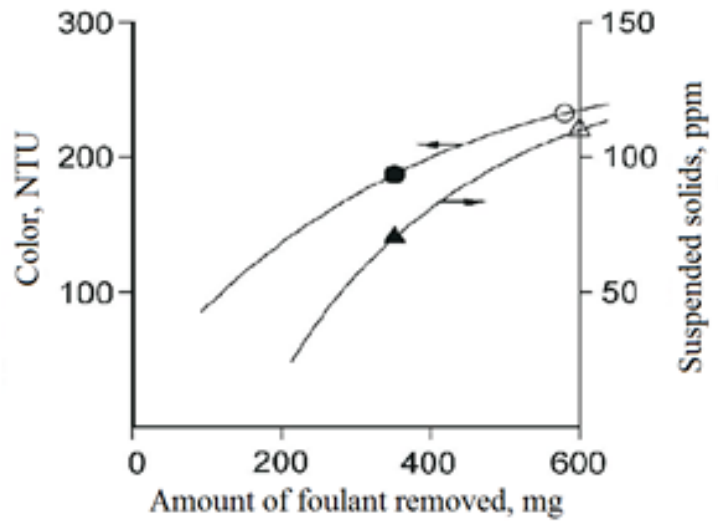

Figure 18: Flushing efficiency: concentration of color and suspended solids in the flush water.

\section{CONCLUSIONS}

State-of-the-art water treatmenr review reveals new tendencies in membrane techniques development that consist of optimum selection of membrane type and module configuration for different applications and operational conditions (feedwater composition, recovery, pressure etc.) High operational costs of membrane facilities and large amounts of effluents are attributed to fouling and scaling in membrane channels.

Lengthy research devoted to membrane fouling reveals that fouling mechanisms depend not only on hydrodynamic conditions in membrane channel, but 
also on membrane material sorption characteristics and channel geometry. The existing spiral wound modules used in RO, NF and UF facilities are very susceptible to fouling, making them useless in treating surface water containing high organics, bacteria, and suspended matter without proper pretreatment to remove these impurities.

Main disadvantages of spiral wound modules are attributed to presence of spacer mesh in the channel that traps fouling particles and increases cross-flow resistance in the module.

Results of conducted studies could be used to introduce new water treatment techniques to directly treat natural water with high fouling and scaling potential using proposed "open-channel" spiral wound modules tailored by nanofiltration and reverse osmosis membranes. Elimination of the "dead areas" responsible for scale formation provides a new solution to increase recovery and utilize concentrate [15].

Introduction of new open-channel modules into water treatment practice suggests a new approach to treat wastewater with high fouling potential without the chance of encountering fouling problems throughout a long period of stable and reliable operation [16].

\section{REFERENCES}

[1] Pervov A. Scale formation prognosis and cleaning procedure schedules in RO systems operation. Desalination 1991; 83: 77-118. http://dx.doi.org/10.1016/0011-9164(91)85087-B

[2] Pervov AG, Melnikov AG. The determination of the required foulant removal degree in RO feed pretreatment, IDA world conference on Desalination and Water reuse August 25-29, 1991, Washington. Pretreatment and fouling.

[3] Harries RC. A field trial of seeded reverse osmosis for the desalination of a scaling-type mine water. Desalination 1985; 56: 227-236 http://dx.doi.org/10.1016/0011-9164(85)85027-X

[4] Futselaar H, Schonewille H, Meer W. Direct capillary nanofiltration for surface water. Desalination 2003; 157: 135136.

http://dx.doi.org/10.1016/S0011-9164(03)00392-8
[5] Bruggen B, Hawrijik I, Cornelissen E, Vandecasteele C. Direct nanofiltration of surface water using capillary membranes: comparison with flat sheet membranes. Sep Pur Tech 2003; 157: 135-136.

[6] Bonne PAC, Hiemstra P, Hoek JP, Hofman JAMH. Is direct nanofiltration with air flush an alternative for household water production for Amsterdam? Desalination 2003; 152: 236-269. http://dx.doi.org/10.1016/S0011-9164(02)01072-X

[7] Potts DE, Ahlert RC, Wang SS. Acritical review of fouling of reverse osmosis membranes. Desalination 1981; 36: 235264.

http://dx.doi.org/10.1016/S0011-9164(00)88642-7

[8] Riddle RA. Open channel ultrafiltration for reverse osmosis pretreatment, IDA world conference on Desalination and Water reuse August 25-29, 1991, Washington. Pretreatment and fouling.

[9] Bian R, Yamamoto K, Watanabe Y. The effect of shear rate on controlling the concentration polarization and membrane fouling/ Proc/ of the conf. on Membranes in Drinking and Industrial Water Production, Paris, France, 3-6 October 2000, Vol. 1, 421-432.

[10] Pervov AG. A simplified RO process design based on understanding of fouling mechanisms. Desalination 1999; 126: 227-247. http://dx.doi.org/10.1016/S0011-9164(99)00179-4

[11] Reitz L. Development of a broad-spectrum antiscalant for reverse osmosis system."12-th Annu. Conf. Water Supply Improv. Assoc., Orlando, Fla, May 13-18, 1984. Tech. Proc. vol.1: Sess. 1-6". Topsfield, Mass. s.a., F 1-26.

[12] Pervov AG, Andrianov AP, Efremov RV. A new solution for Caspian Sea desalination: low pressure membranes, Presented at the European Conference on Desalination and the Environment: Fresh Water for All, Malta, May 4-8, 2003. EDS, IDA. Desalination 2003; 157: 377-384. http://dx.doi.org/10.1016/S0011-9164(03)00420-X

[13] Hilal N, Mohammad AW, Atkina B, Darwish NA. Using atomic force microscopy towards improvement in nanofiltration membranes properties for desalination pre-treatment: A review. Desalination 2003; 157: 137-144. http://dx.doi.org/10.1016/S0011-9164(03)00393-X

[14] Hilal N, Al-Khatib L, Atkin BP, Kochkodan V, Potapchenko N Photochemical modification of membrane surfaces for (bio)fouling reduction: a nano-scale study using AFM. Desalination 2003; 156: 65-72. http://dx.doi.org/10.1016/S0011-9164(03)00434-X

[15] Pervov A. Utilization of concentrate in reverse osmosis in water desalination systems. Tianjin IDA World Congress 2013 jn Desalination and Water Reuse, October 20-25, China 2013, TIAN 13-216.

[16] Pervov A, Matveyev N. Use of reverse osmosis to treat domestic wastewater for local utilities and in small industries. Tianjin IDA World Congress 2013 in Desalination and Water Reuse, October 20-25, China 2013.

\section{DOl: http://dx.doi.org/10.6000/1929-6037.2014.03.01.6}

(c) 2014 Alexei Pervov; Licensee Lifescience Global.

This is an open access article licensed under the terms of the Creative Commons Attribution Non-Commercial License (http://creativecommons.org/licenses/by-nc/3.0/) which permits unrestricted, non-commercial use, distribution and reproduction in any medium, provided the work is properly cited. 